\title{
Conservative therapeutic management of carpal tunnel syndrome
}

\author{
Manejo terapêutico conservador da síndrome do túnel do carpo \\ Roberto Sérgio Martins ${ }^{1}$, Mário Gilberto Siqueira ${ }^{1}$
}

\begin{abstract}
Carpal tunnel syndrome is the most prevalent nerve compression and can be clinically or surgically treated. In most cases, the first therapeutic alternative is conservative treatment but there is still much controversy regarding the most effective modality of this treatment. In this study, we critically evaluated the options of conservative treatment for carpal tunnel syndrome, aiming to guide the reader through the conventional options used in this therapy.
\end{abstract}

Keywords: carpal tunnel syndrome; median nerve; conservative treatment.

\section{RESUMO}

A síndrome do túnel do carpo é a compressão de nervo mais prevalente e seu tratamento pode ser clínico ou cirúrgico. Na maioria dos casos o tratamento conservador é a primeira alternativa terapêutica mas ainda há muitas controvérsias a respeito do tratamento mais eficaz. Neste estudo avaliamos de forma crítica as opções de tratamento conservador da síndrome do túnel do carpo, objetivando guiar o leitor no uso racional deste tipo de terapêutica.

Palavras-chave: síndrome do túnel do carpo; nervo mediano; tratamento conservador.

In the wrist, the carpal bones are arranged to form the floor and sides of an arch-shaped channel. The flexor retinaculum, or transverse carpal ligament, is a fibrous band that attaches the medial and lateral eminences of this bone arch, forming the palmar roof of a narrow opening called the carpal tunnel ${ }^{1}$. This tunnel encloses the median nerve and nine tendons of the flexor finger muscles. Any pathophysiological condition or anatomic abnormality that causes enlargement of the carpal tunnel components, reduces its cross-section or raises the pressure inside it, can lead to symptomatic compression of the median nerve - carpal tunnel syndrome (CTS).

Carpal tunnel syndrome is the most common compressive neuropathy, with a prevalence of $5.8 \%$ in adult women and $0.6 \%$ for men ${ }^{2}$. Generally, CTS is characterized by an insidious onset and the diagnosis is completely clinical. Usually, the patient complains of tingling and numbness in the hand, especially in the first three fingers and radial half of the fourth finger (the cutaneous distribution of the median nerve), commonly associated with worsening at night. Physical examination frequently reveals positive provocative test results, such as Tinel's sign, Phalen's test and the carpal compression test. Sensory loss and, less frequently, motor deficit and thenar atrophy, can be observed in neurologic examination ${ }^{1}$.
In most cases, conservative treatment is the first therapeutic alternative, especially in patients without significant sensory or motor deficits. However, despite its prevalence and the impact of CTS on health systems, there is still much controversy regarding optimal therapy. This can be explained by the fact that most of our knowledge about the treatment of CTS has been based on uncontrolled trials and retrospective studies leading to conflicting conclusions. Accordingly, this review aims to provide a comprehensive and critical analysis of conservative treatment in the management of the CTS.

\section{Corticosteroid injection}

Corticosteroid injection has been used in the conservative treatment of CTS to reduce symptoms. The exact mechanism of this therapy remains unclear but the anti-inflammatory effect is probably the most significant factor in relieving symptoms ${ }^{3}$. Different types of corticoids have been used, such as hydrocortisone, dexamethasone, methylprednisolone or triamcinolone, usually in association with a local anesthetic, but there is no objective standard for defining the ideal dose or specific drug $^{3,4}$. A unique study showed no difference when comparing shorter- versus longer-acting corticosteroids as well as low and 
high doses ${ }^{5}$ and, therefore, the authors recommended the former due to the potentially-less collateral effects. Usually, we use 1 ampoule with $4 \mathrm{mg}$ dexamethasone with $5 \mathrm{ml}$ of xylocaine.

Corticosteroid injections are usually performed according to specific parameters. The injection can be targeted at the anterior flexor crest of the wrist on the ulnar side of the palmar tendon, an easily-palpable structure. Due to the high risk of nerve injury, injection between the tendons of the radial long carpal and the long palmar muscle should be avoided. The angle of insertion of the needle is $45^{\circ}$ and it is introduced about $1 \mathrm{~cm}$ in depth. The most common risks of corticosteroid injection are nerve or tendon injuries. Inadvertent injection of the median nerve causes immediate shock pain, with the risk of sensory and motor deficits and persistent neuropathic pain. Use in diabetic patients should be avoided and some patients may experience temporary worsening of pain for two to three days after the injection. Manual effort should be avoided for one to two days after the procedure ${ }^{3}$. The application can be repeated in one to three months but more than two or three applications are not recommended owing to the potential adverse effects ${ }^{3}$.

In seven studies of adequate methodology $y^{6,7,8,9,10,11,12,13}$, Piazzini et al. ${ }^{11}$ concluded that corticosteroid injection in the carpal tunnel can be considered as an effective treatment. However, no significant clinical benefit was found for corticosteroid injections compared with other treatments, including splint immobilization ${ }^{14,15}$. In addition, adverse effects such as infection, allergic reaction, osteonecrosis, tendon rupture, and nerve or tendon injury should be considered ${ }^{3}$. Therefore, this treatment has been used as a temporary solution, as the effects are short term (months) and, as such, it is a good option in transient conditions that lead to CTS, such as pregnancy or in patients who present with local or systemic risks for surgery.

\section{Oral supplements and medications}

Vitamin B6 (pyridoxine) acts as a coenzyme in numerous enzymatic reactions of lipid, amino acids and glucose metabolism that are part of the neural function ${ }^{16,17}$. Conclusions about the effects of vitamin B6 in CTS patients were established based on case reports or researches with small numbers of participants. The improvement observed in some cases was thought to be due to resolution of some previously-undiagnosed neuropathy or by analgesic action on the painful pathway ${ }^{17}$. Despite this fact, some authors still recommend this therapy, based on clinical response, and the dose usually used is $200 \mathrm{mg} /$ day. The most common adverse effects are numbness, paraesthesia, and other symptoms related to sensory neuropathy, which usually disappear upon discontinuation of the supplement ${ }^{17}$.

Oral diuretics have been used in the treatment of CTS to reduce edema and hence the tunnel's content. Trichlormethiazide, a diuretic with properties similar to those of hydrochlorothiazide, was preferentially used in some comparative studies but the results were ineffective in the management of the $\mathrm{CTS}^{4,11}$. Oral steroids, even at low doses, are more effective than nonsteroidal anti-inflammatory drugs (NSAIDs) and diuretics in the conservative treatment of $\mathrm{CTS}^{11}$. However, the risk of side effects limits their long-term use ${ }^{18}$. Although NSAIDs are not effective, they may be useful in patients with CTS-associated tendinitis or tenosynovitis to relieve symptoms ${ }^{4,18}$.

\section{Exercise therapy and mobilization techniques}

The rationale for using dynamic exercises as a treatment of CTS is derived from cadaver and in vivo ultrasound studies showing median nerve and tendon excursions through the carpal tunnel during the wrist and/or finger movement ${ }^{19,20,21,22}$. According to several authors, gliding exercises improve symptoms by preventing, or stretching, the adhesions among the tendons and median nerve, decreasing tenosynovial edema, improving venous return and, thus, reducing pressure inside the carpal tunnel ${ }^{19,20,21,22,23,24,25,26,27}$.

Basically, the exercises involve a sequence of finger movements (for tendon gliding) and wrist and fingers movements (for median nerve gliding) (Figures $1 \mathrm{~A}$ and B). In general, both exercises had been applied concurrently but in some studies, one of the therapies was adopted as the only task ${ }^{23}$. Patients were instructed to practice each exercise, with ten repetitions, three to five times daily. Each position was sustained for five seconds ${ }^{23}$.

Conflicting results concerning this therapy have been published. According to Huisstede et al. ${ }^{3}$, this fact is explained because some studies had poor methodological quality and evaluated this therapy in association with other managements, such as the combination of a splint, ultrasound therapy, and tendon and nerve gliding exercises ${ }^{3,25}$. Some studies did not show improvement ${ }^{23}$ and one even showed worsening of the functional status ${ }^{28}$. According to Ashworth, nerve and tendon gliding exercises were less effective than splint immobilization in relieving symptoms and improving hand function ${ }^{4}$. In the 2012 Cochrane Review, Page et al. ${ }^{29}$ concluded that there was limited evidence that justified the use of exercise and mobilization interventions for CTS. However, the authors suggested that consideration of this therapy should be based on clinician's experience and patient's preference.

\section{Wrist immobilization}

Wrist immobilization is the most frequently-adopted conservative therapy for $\mathrm{CTS}^{30}$. The rationale for splinting was established based on the following: avoiding the extremes of wrist position reduces the pressure within the carpal tunnel and the neutral wrist position improves hemodynamic parameters, reducing the edema and minimizing nerve friction and compression $^{31,32}$. Two major types of orthoses used as a fingerless glove are described in the treatment of carpal tunnel syndrome: the hand brace and wrist splint. The brace, less frequently used, is made of soft materials without rigid components, unlike the splint ${ }^{33}$. The purpose of both devices is the same: to eliminate the range of motion in one direction. A single study compared the effectiveness of the brace to a splint and there was no difference between these treatments ${ }^{33}$. 

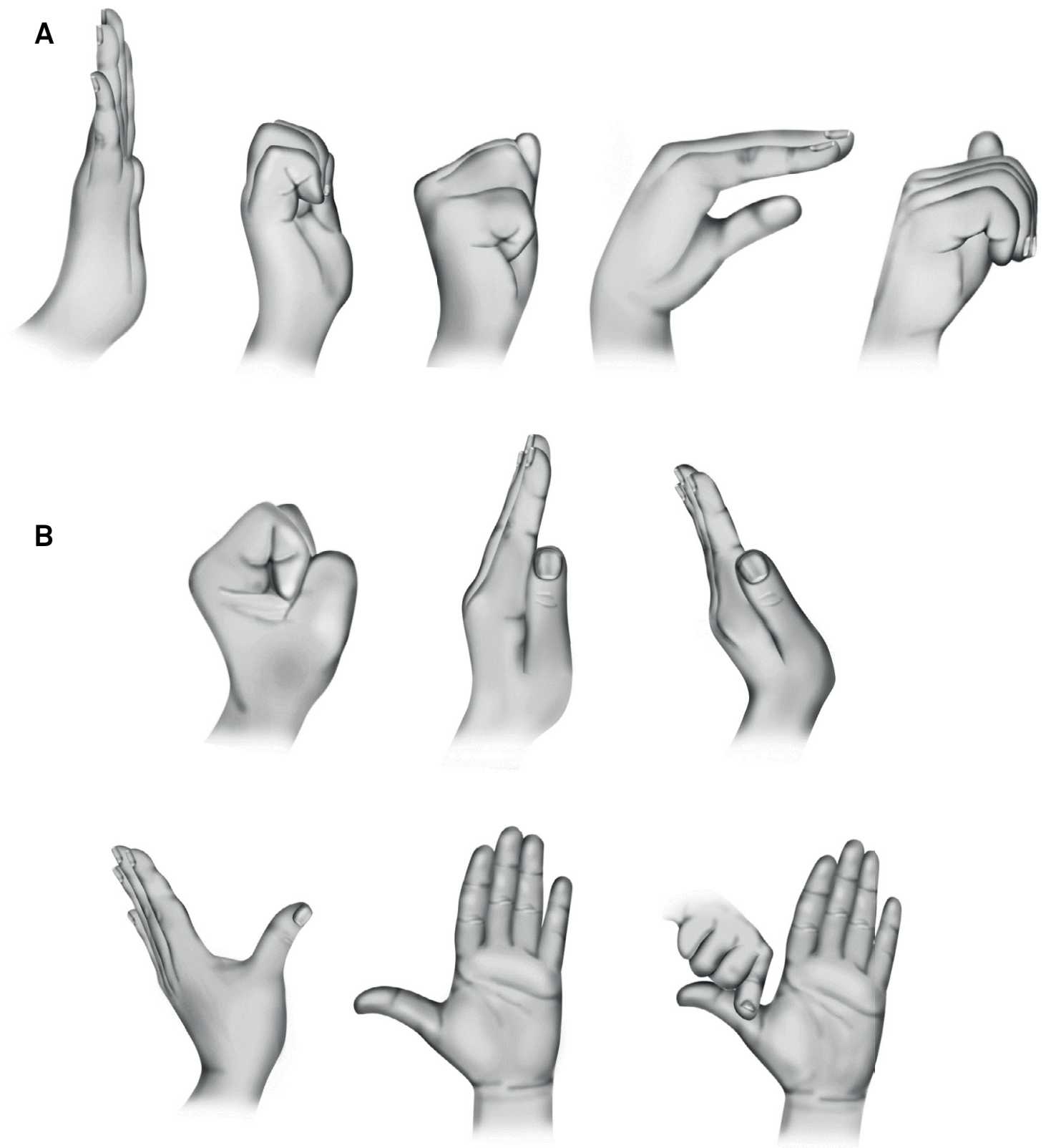

Figure 1. A) Example of the sequence of finger movements during tendon gliding exercises; B) Example of the sequence of finger movements during median nerve gliding exercises. In the last sequence, the thumb is pulled back gently. Adapted from: Akalin E et al. ${ }^{23}$

Wrists splints can be prefabricated or produced by modeling a heated thermoplastic component on the patient's wrist (Figure 2). Discontinuation of treatment due to cutaneous intolerance to the splint has been reported in less than $1 \%$ of patients ${ }^{33}$. Usually, prefabricated splints contain a volar rod that gives firmness, but may cause discomfort in some patients. However, in general, both models are well tolerated. Typically, the splints are manufactured for use in the neutral position but this recommendation is based on a single randomized controlled trial considered to be of poor quality ${ }^{3,30,34}$. Wrists splints usually are used for at least a three-month period $^{30,33}$ at night-time. According to Huisstede et al., ${ }^{29}$ there is no evidence supporting the full-time use of wrist splint compared to a night-only period.
Despite the prevalence of CTS, the efficacy of different therapeutic modalities, including wrist immobilization, lacks prospective and well-controlled studies. Although widely used in clinical practice, the full effectiveness of the splint has not yet been consistently demonstrated in systematic reviews. Page et al. ${ }^{35}$, in a 2012 Cochrane review, found limited evidence for splinting over a short period versus no treatment or other conservative treatments. However, previous reviews have shown moderate evidence supporting the use of wrist splints in the treatment of CTS ${ }^{11,30}$. Furthermore, as noted by Roll and Hardison, a randomized and controlled trial was not included in any of these reviews ${ }^{36,37}$. A trial by Hall et al. showed that the use of a wrist splint improved symptoms in CTS patients ${ }^{37}$. There was no support for the long-term use of wrist splints in a review by Page et al. ${ }^{38}$. 


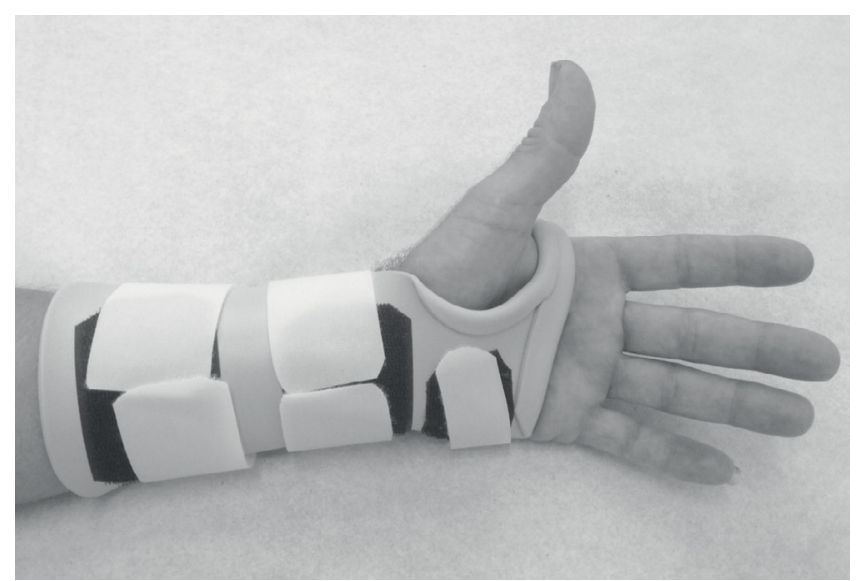

Figure 2. A custom-made splint manufactured with thermoplastic material.

\section{Other conservative treatments}

\section{Low-level laser therapy}

In general, laser therapy acts by transferring energy, inducing local effects including increased production of endorphins, serotonin and several mediators reducing the inflammatory reaction and increasing analgesia ${ }^{39}$. Low power lasers have been used in the treatment of CTS, suitable for biostimulating action. An important detail in the analysis of the treatment is the power density of the dose, which should be sufficient to cross through the different tissues to the target organ. The dose generally used is $8-10 \mathrm{~J} / \mathrm{cm}^{2}$ with a wavelength ranging from $830-904 \mathrm{~nm}^{39}$.

This low-level laser therapy is applied through a specific probe at different points (usually three) in the wrist where the median nerve travels superficially ${ }^{40}$. The duration of application at each point is 90 seconds $^{40}$. The purpose of the treatment is to reduce the inflammatory process and edema, but some authors have used the laser as a tool to stimulate points used in acupuncture with the aim of improving associated pain $^{41}$. Positive effects of laser on axonal regeneration have been demonstrated in experimental studies ${ }^{42,43}$, however it is not yet clear whether the laser energy is sufficient to reach the median nerve in humans ${ }^{39}$.

The results with this type of therapy are conflicting and may be explained by the heterogeneity of factors such as laser font, dose intensity, duration of application, and different methodologies used to evaluate the results ${ }^{39}$. There is still uncertainty whether the structures that are the target of treatment in humans are, in fact, reached by the transferred energy ${ }^{39}$. Thus, evidence of treatment efficacy still needs to be demonstrated and cost-effectiveness needs to be assessed ${ }^{11,40,41,42,43}$.

\section{Ultrasound}

Therapeutic ultrasound is a physical therapy that uses sound waves administered by a specific transducer and absorbed by surrounding tissues. The pathophysiological premise that justifies its use as a therapeutic option in patients with CTS is still controversial ${ }^{38}$. Some authors argue that the effect of ultrasound is secondary to increased local temperature resulting in increased blood flow rates, metabolism and neural regeneration, while other researchers claim that the action is due to an anti-inflammatory effect ${ }^{44,45}$.

Because of the limited number of studies, there are still a number of doubts about the therapeutic use of ultrasound in CTS, especially with regard to the number and duration of sessions required. According to the systematic review carried out by Page et al. ${ }^{38}$, there is poor quality evidence to recommend therapeutic ultrasound over other conservative treatments used in CTS, a conclusion also observed in another recent trial ${ }^{44}$. No adverse effects have been reported in the reviews by Page et al..$^{38}$, but only three reports were evaluated.

In conclusion, due to the scarcity of quality evidence in the current literature, doubts still exist about which conservative treatment is most appropriate for CTS, especially to treat CTS in the long term. The recommendation should be based on the intensity of symptoms, severity of the clinical presentation and the patient's preference. Despite the low level of evidence, corticosteroid injection and wrist immobilization are the tools to be used preferentially in the conservative treatment of CTS.

\section{References}

1. Middleton SD, Anakwe RE. Carpal tunnel syndrome. BMJ. 2014;6;349:g6437. https://doi.org/10.1136/bmj.g6437.

2. Krom MC, Knipschild PG, Kester AD, Thijs CT, Boekkooi PF, Spaans F. Carpal tunnel syndrome: prevalence in the general population. J Clin Epidemiol. 1992;45(4):373-6. https://doi.org/10.1016/0895-4356(92)90038-0

3. Huisstede BM, Fridén J, Coert JH, Hoogvliet P, European HANDGUIDE Group. Carpal tunnel syndrome: hand surgeons, hand therapists, and physical medicine and rehabilitation physicians agree on a multidisciplinary treatment guideline-results from the European Handguide Study. Arch Phys Med Rehabil. 2014;95(12):2253-63. https://doi.org/10.1016/j.apmr.2014.06.022

4. Ashworth NL. Carpal tunnel syndrome. Am Fam Physician. 2016;94(10):830-1.
5. O'Gradaigh D, Merry P. Corticosteroid injection for the treatment of carpal tunnel syndrome. Ann Rheum Dis. 2000;59(11):918-9. https://doi.org/10.1136/ard.59.11.918

6. Armstrong T, Devor W, Borschel L, Contreras R. Intracarpal steroid injection is safe and effective for short-term management of carpal tunnel syndrome. Muscle Nerve. 2004;29(1):82-8. https://doi.org/10.1002/mus.10512

7. Breuer B, Sperber K, Wallenstein S, Kiprovski K, Calapa A, Snow B et al. Clinically significant placebo analgesic response in a pilot trial of botulinum $B$ in patients with hand pain and carpal tunnel syndrome. Pain Med. 2006;7(1):16-24. https://doi.org/10.1111/j.1526-4637.2006.00084.x

8. Dammers JW, Veering MM, Vermeulen M. Injection with methylprednisolone proximal to the carpal tunnel: randomized double blind trial. BMJ. 1999;319(7214):884-6. https://doi.org/10.1136/bmj.319.7214.884 
9. Gökoğlu F, Fındıkoğlu G, Yorgancoğlu ZR, Okumuș M, Ceceli E, Kocaoğlu S. Evaluation of iontophoresis and local corticosteroid injection in the treatment of carpal tunnel syndrome. Am J Phys Med Rehabil. 2005;84(2):92-6. https://doi.org/10.1097/01.PHM.0000151942.49031.DD

10. Nalamachu S, Crockett RS, Mathur D. Lidocaine patch $5 \%$ for carpal tunnel syndrome: how it compares with injections: a pilot study. J Fam Pract. 2006;55(3):209-14.

11. Piazzini DB, Aprile I, Ferrara PE, Bertolini C, Tonali P, Maggi L et al. A systematic review of conservative treatment of carpal tunnel syndrome. Clin Rehabil. 2007;21(4):299-314. https://doi.org/10.1177/0269215507077294

12. Wong SM, Hui AC, Tang A, Ho PC, Hung LK, Wong KS et al. Local vs. systemic corticosteroids in the treatment of carpal tunnel syndrome. Neurology. 2001;56(11):1565-7. https://doi.org/10.1212/WNL.56.11.1565

13. Wong SM, Hui ACF, Lo SK, Chiu JH, Poon WF, Wong L. Single vs. two steroid injections for carpal tunnel syndrome: a randomised clinical trial. Int J Clin Pract. 2005;59(12):1417-21. https://doi.org/10.1111/j.1368-5031.2005.00696.x

14. Marshall S, Tardif G, Ashworth N. Local corticosteroid injection or carpal tunnel syndrome. Cochrane Database Syst Rev. 2007(2):CD001554.

15. Sevim S, Dogu O, Camdeviren H, Kaleagasi H, Aral M, Arslan E et al. Long-term effectiveness of steroid injections and splinting in mild and moderate carpal tunnel syndrome. Neurol Sci. 2004;25(2):48-52. https://doi.org/10.1007/s10072-004-0229-0

16. Amadio PC. Pyridoxine as an adjunct in the treatment of carpal tunnel syndrome. J Hand Surg Am. 1985;10(2):237-41. https://doi.org/10.1016/S0363-5023(85)80112-X

17. Ryan-Harshman M, Aldoori W. Carpal tunnel syndrome and vitamin B6. Can Fam Physician. 2007;53(7):1161-2.

18. O'Connor D, Marshall S, Massy-Westropp N. Non-surgical treatment (other than steroid injection) for carpal tunnel syndrome. Cochrane Database Syst Rev 2003(1):CD003219. https://doi.org/10.1002/14651858.CD003219

19. Horng YS, Hsieh SF, Lin MC, Chang YW, Lee KC, Liang HW. Ultrasonographic median nerve changes under tendon gliding exercise in patients with carpal tunnel syndrome and healthy controls. J Hand Ther. 2014;27(4):317-23. https://doi.org/10.1016/j.jht.2014.07.007

20. Szabo RM, Bay BK, Sharkey NA, Gaut C. Median nerve displacement through the carpal canal. J Hand Surg Am. 1994;19(6):901-6. https://doi.org/10.1016/0363-5023(94)90087-6

21. Wright WT, Glowczewskie F, Wheeler D, Miller G, Cowin D. Excursion and strain of the median nerve. J Bone Joint Surg Am. 1996;78(12):1897-903. https://doi.org/10.2106/00004623-199612000-00013

22. Yoshii Y, Villarraga HR, Henderson J, Zhao C, An KN, Amadio PC. Ultrasound assessment of the displacement and deformation of the median nerve in the human carpal tunnel with active finger motion. J Bone Joint Surg (Am). 2009;91(12):2922-30. https://doi.org/10.2106/JBJS.H.01653

23. Akalin E, El O, Peker O, Senocak O, Tamci S, Gülbahar S et al. Treatment of carpal tunnel syndrome with nerve and tendon gliding exercises. Am J Phys Med Rehabil. 2002;81(2):108-13. https://doi.org/10.1097/00002060-200202000-00006

24. Heebner ML, Roddey TS. The effects of neural mobilization in addition to standard care in persons with carpal tunnel syndrome from a community hospital. J Hand Ther. 2008;21(3):229-40. https://doi.org/10.1197/j.jht.2007.12.001

25. Pinar L, Enhos A, Ada S, Güngör N. Can we use nerve gliding exercises in women with carpal tunnel syndrome? Adv Ther. 2005;22(5):467-75. https://doi.org/10.1007/BF02849867

26. Rozmaryn LM, Dovelle S, Rothman ER, Gorman K, Olvey KM, Bartko JJ. Nerve and tendon gliding exercises and the conservative management of carpal tunnel syndrome. J Hand Ther. 1998;11(3):171-9. https://doi.org/10.1016/S0894-1130(98)80035-5
27. Wehbé MA, Hunter JM. Flexor tendon gliding in the hand. Part II. Differential gliding. J Hand Surg Am. 1985;10(4):575-9. https://doi.org/10.1016/S0363-5023(85)80086-1

28. Horng YS, Hsieh SF, Tu YK, Lin MC, Horng YS, Wang JD. The comparative effectiveness of tendon and nerve gliding exercises in patients with carpal tunnel syndrome: a randomized trial. Am J Phys Med Rehabil. 2011;90(6):435-42. https://doi.org/10.1097/PHM.0b013e318214eaaf

29. Page MJ, O'Connor D, Pitt V, Massy-Westropp N. Exercise and mobilisation interventions for carpal tunnel syndrome. Cochrane Database Syst Rev. 2012;13(6):CD009899. https://doi.org/10.1002/14651858.CD009899

30. Huisstede BM, Hoogvliet P, Randsdorp MS, Glerum S, van Middelkoop M, Koes BW. Carpal tunnel syndrome. Part I: effectiveness of nonsurgical treatments: a systematic review. Arch Phys Med Rehabil. 2010;91(7):981-1004. https://doi.org/10.1016/j.apmr.2010.03.022

31. Manente G, Torrieri F, Di Blasio F, Staniscia T, Romano F, Uncini A. An innovative hand brace for carpal tunnel syndrome: a randomized controlled trial. Muscle Nerve. 2001;24(8):1020-5. https://doi.org/10.1002/mus.1105

32. Schmid AB, Elliott JM, Strudwick MW, Little M, Coppieters MW. Effect of splinting and exercise on intraneural edema of the median nerve in carpal tunnel syndrome: an MRI study to reveal therapeutic mechanisms. J Orthop Res. 2012;30(8):1343-50. https://doi.org/10.1002/jor.22064

33. De Angelis MV, Pierfelice F, Di Giovanni P, Staniscia T, Uncini A. Efficacy of a soft hand brace and a wrist splint for carpal tunnel syndrome: a randomized controlled study. Acta Neurol Scand. 2009;119(1):68-74. https://doi.org/10.1111/j.1600-0404.2008.01072.x

34. Burke DT, Burke MM, Stewart GW, Cambré A. Splinting for carpal tunnel syndrome: in search of the optimal angle. Arch Phys Med Rehabil. 1994;75(11):1241-4. https://doi.org/10.1016/0003-9993(94)90012-4

35. Page MJ, Massy-Westropp N, O'Connor D, Pitt V. Splinting for carpal tunnel syndrome. Cochrane Database Syst Rev. 2012;11(7):CD010003. https://doi.org/10.1002/14651858.CD010003

36. Roll SC, Hardison ME. Effectiveness of occupational therapy interventions for adults with musculoskeletal conditions of the forearm, wrist, and hand: a systematic review. Am J Occup Ther. 2017;71(1):7101180010p1-12. https://doi.org/10.5014/ajot.2017.023234

37. Hall B, Lee HC, Fitzgerald H, Byrne B, Barton A, Lee AH. Investigating the effectiveness of full-time wrist splinting and education in the treatment of carpal tunnel syndrome: a randomized controlled trial. Am J Occup Ther. 2013;67(4):448-59. https://doi.org/10.5014/ajot.2013.006031

38. Page MJ, O'Connor D, Pitt V, Massy-Westropp N. Therapeutic ultrasound for carpal tunnel syndrome. Cochrane Database Syst Rev. 2013;3(3):CD009601. https://doi.org/10.1002/14651858.CD009601

39. Chang WD, Wu JH, Jiang JA, Yeh CY, Tsai CT. Carpal tunnel syndrome treated with a diode laser: a controlled treatment of the transverse carpal ligament. Photomed Laser Surg. 2008;26(6):551-7. https://doi.org/10.1089/pho.2007.2234

40. Yagci I, Elmas O, Akcan E, Ustun I, Gunduz OH, Guven Z. Comparison of splinting and splinting plus low-level laser therapy in idiopathic carpal tunnel syndrome. Clin Rheumatol 2009;28(9):1059-65. https://doi.org/10.1007/s10067-009-1213-0

41. Naeser MA, Hahn KA, Lieberman BE, Branco KF. Carpal tunnel syndrome pain treated with low-level laser and microamperes transcutaneous electric nerve stimulation: A controlled study. Arch Phys Med Rehabil. 2002;83(7):978-88. https://doi.org/10.1053/apmr.2002.33096 
42. Gigo-Benato D, Geuna S, de Castro Rodrigues A, Tos P, Fornaro M, Boux $E$ et al. Low-power laser biostimulation enhances nerve repair after end-to-side neurorrhaphy: a double-blind randomized study in the rat median nerve model. Lasers Med Sci. 2004;19(1):57-65. https://doi.org/10.1007/s10103-004-0300-3

43. Oliveira FB, Pereira VM, Trindade AP, Shimano AC, Gabriel RE, Borges AP. Action of therapeutic laser and ultrasound in peripheral nerve regeneration. Acta Ortop Bras. 2012;20(2):98-103. https://doi.org/10.1590/S1413-78522012000200008
44. Armagan O, Bakilan F, Ozgen M, Mehmetoglu O, Oner S. Effects of placebo-controlled continuous and pulsed ultrasound treatments on carpal tunnel syndrome: a randomized trial. Clinics (São Paulo). 2014;69(8):524-8. https://doi.org/10.6061/clinics/2014(08)04

45. Oztas O, Turan B, Bora I, Karakaya MK. Ultrasound therapy effect in carpal tunnel syndrome. Arch Phys Med Rehabil. 1998;79(12):1540-4. https://doi.org/10.1016/S0003-9993(98)90416-6 